inability to walk except with great difficulty. In the severest cases, the patients cannot even stand, or allow the weight of the body to fall upon the pelvis.

There is also a marked difference in the time required for the bones to become united in the two classes of cases. Traumatic cases recover quite readily, unless life is destroyed by some injury to the pelvic viscera. Cooper's case was nearly well in three months. The patient whose case is reported at the beginning of this paper was in a fair way to complete recovery at the end of two and a half months. On the other hand, it is only the lightest pathological cases that recover as readily; they often require many months. Barker reports a case that took fifteen years for recovery; and Debout two cases which occupied seventeen and fifty years respectisely. In the former class, nature soon rallies from the shock, and sets to work to repair the damage; while in the latter class nature does nothing of the kind till pregnancy is terminated, and in many cases not even then.

The treatment required in both instances is similar, although the puerperal class will generally necessitate its continuance much longer than the traumatic. Rest and a pelvic bandage are the two important elements in the treatment. The rest should be absolute, in bed, and continued at least three months in traumatic cases. The bandage should be firm, and should fit closely. It should be ten or twelve inches wide, and have perineal straps to present its slipping upward above the crest of the ilium. It should be worn after the patient gets upon his feet, and as long as he feels any sensation of pain or weakness about the pelvis.

\title{
A CASE OF PICA.
}

BY A. N. gould, M. D., Centre effinghaM, N. H.

Miss M. E. M. applied to me in August, 1875. She was forty-three years old. Her health had generally been good. She complained of drowsiness; she slept easily in the daytime, especially after dinner. She commenced to menstruate when fifteen or sixteen years old, and was generally regular. Within a year she had flowed very freely, the menstrual flow having at first a " muddy" color, as the patient expresses it, with some red tint ; toward the close of the catamenia it was colorless. For two years she liad had a longing for innutritious articles. At first she ate charcoal. At present fine sand was craved. Dyspnoca on going up-stairs was marked. The bowels were costive. The tongue was clean. I prescribed compound spirits of lavender, and chloric ether for the dyspnoea, with a laxative and a preparation of iron.

December 12th. I visited the patient at her home. She had taken the medicine as ordered. The appetite for the sand remained. I ob- 


\section{Progress in the Treatment of Diseases of the Throat. [April 13,}

tained a specimen for examination. I left about two ounces of carbonate of iron to take the place of the sand, saying that she might take a teaspoonful three times a day.

January 24, 1876. The carbonate of iron was eaten in four days, and the sand eating was again resumed. I questioned her in regard to the amount of sand eaten in a day, and she replied that she could eat a cupful, but feared her supply would fail before winter was over. She ate three or four tablespoonfuls in a day, and there were not many days when she did not gratify her depraved taste, as the habit was too strong to be long discontinued. Her lips were somewhat pale, although she had gained in flesh since the habit was formed. She said that while she had the carbonate of iron she did not want the sand, and that she would give it up if she could have enough of the substitute, although she did not like the latter so well. I ordered two pounds of iron for her especial benefit. She asserted she had eaten " nearly a bushel" of the sand.

She was first seized with a longing to eat the sand when she saw some workmen putting it upon the road near her house. It was only this particular kind that she craved. She laid in a supply for the winter, and baked it to destroy anything injurious that might be in it. She appeared lively, strong, and well. There was some "bloating" at times, but nothing worthy of special notice. I have not had a convenient opportunity to examine the heart and lungs as yet.

\section{RECENT PROGRESS IN THE TREATMENT OF DISEASES OF THE THROAT. \\ BY F. I. KNIGHT, M. D.}

Extirpation of the Larynx. - CASE VI. (continued). After our paper which appeared in the last number had gone to press, we received a fuller accuunt of Bottini's case. ${ }^{2}$ The age of the patient is stated to have been twenty-four. Bottini employed local anæsthesia, deeming it imprudent to produce general anæsthesia by chloroform. He expresses a prejudice against the trachea-tampon, which is not sustained by the experience, now extensive, of German surgeons in the use of this instrument. The growth in Bottini's case involved the entire larynx, and was pronounced to be genuine sarcoma, which is of extremely rare occurrence in this situation. Bottini also gives an account of some operations on dogs, from which he removed the larynges by means of the galvano-caustic knife, without the slightest hæmorrhage, either primary or secondary.

Case VII. - Langenbeck. ${ }^{3}$ The patient was a man fifty-seven

Concluded from page 393.

Annales des Maladies de l'Oreille et du Larynx, 1875, No. 6, from Giornale della $R$. Academia di Medicina di Torino, May, 1875, No. 14.

- Berliner klinische Wochenschrift, No. 33, 1875. 